$47 / 559562$

PREPARED FOR THE U.S. DEPARTMENT OF ENERGY, UNDER CONTRACT DE-ACO2-76-CHO-3073

PPPL-3110

- UC-427

PPPL-3110

\title{
STABILITY ANALYSIS OF TOROIDICITY-INDUCED ALFVÉN EIGENMODES IN TFTR DT EXPERIMENTS
}

BY

G.Y. FU, C.Z. CHENG, R. BUDNY, ET AL.

JULY 1995
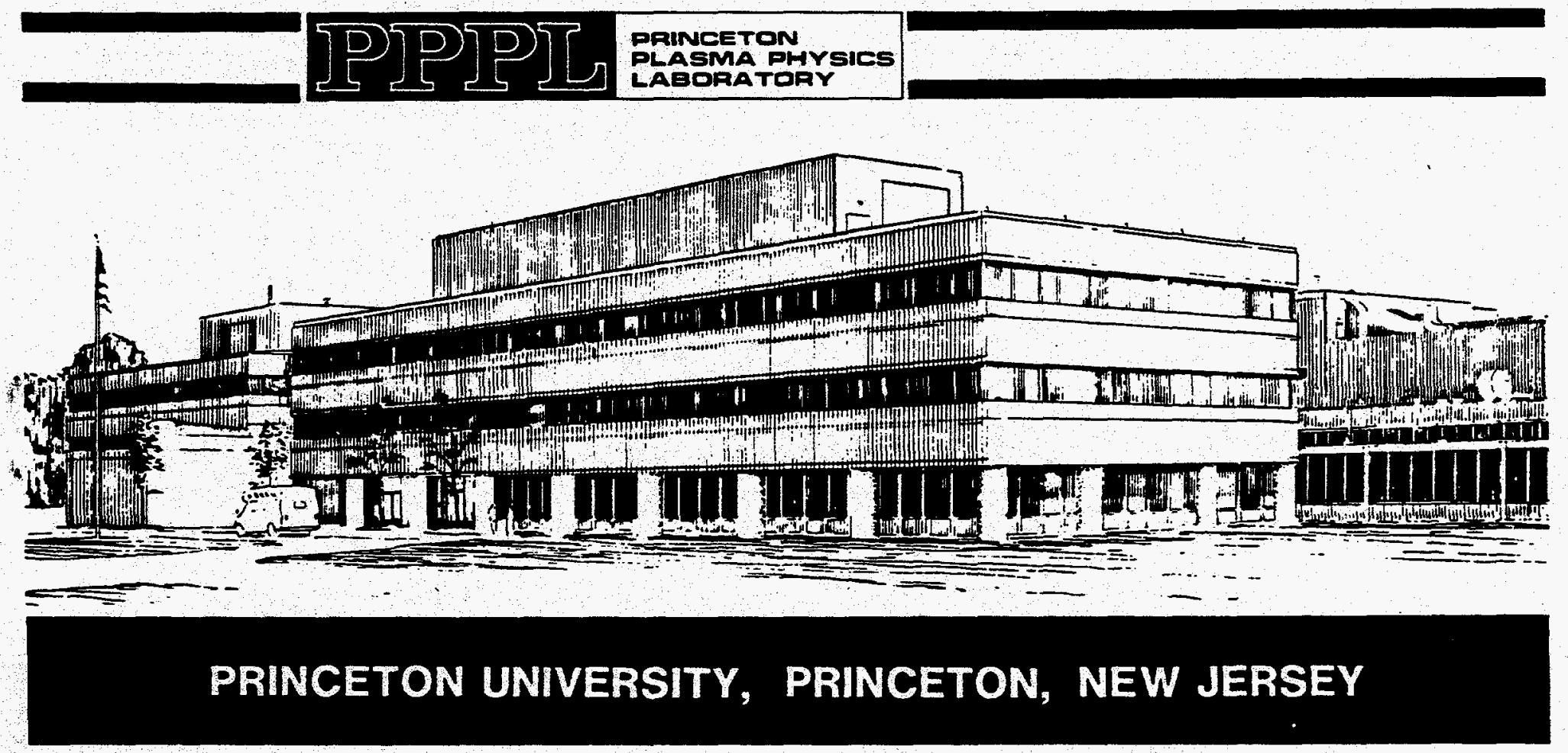


\section{NOTICE}

This report was prepared as an account of work sponsored by an agency of the United States Government. Neither the United States Government nor any agency thereof, nor any of their employees, makes any warranty, express or implied, or assumes any legal liability or responsibility for the accuracy, completeness, or usefulness of any information, apparatus, product, or process disclosed, or represents that its use would not infringe privately owned rights. Reference herein to any specific commercial produce, process, or service by trade name, trademark, manufacturer, or otherwise, does not necessarily constitute or imply its endorsement, recommendation, or favoring by the United States Government or any agency thereof. The views and opinions of authors expressed herein do not necessarily state or reflect those of the United States Government or any agency thereof.

\section{NOTICE}

This report has been reproduced from the best available copy. Available in paper copy and microfiche.

Number of pages in this report: 24

DOE and DOE contractors can obtain copies of this report from:

Office of Scientific and Technical Information

P.O. Box 62

Oak Ridge, TN 37831;

(615) 576-8401.

This report is publicly available from the:

National Technical Information Service

Department of Commerce

5285 Port Royal Road

Springfield, Virginia 22161

(703) $487-4650$ 


\section{DISCLAIMER}

Portions of this document may be illegible in electronic image products. Images are produced from the best available original document. 


\title{
Stability Analysis of Toroidicity-induced Alfvén Eigenmodes in TFTR DT Experiments
}

G. Y. Fu, C. Z. Cheng, R. Budny, Z. Chang, D. S. Darrow, E. Fredrickson, E. Mazzucato, R. Nazikian, and S. Zweben

Princeton Plasma Physics Laboratory, Princeton University

P. O. Box 451

Princeton, New Jersey 08543, U.S.A.

(May 15, 1995)

\begin{abstract}
The toroidicity-induced Alfvén eigenmodes (TAE) with radially extended structure are found to be stable in the Tokamak Fusion Test Reactor Deuterium-Tritium plasmas. A core localized TAE mode is shown to exist near the center of the plasma at small magnetic shear and finite plasma beta, which can be destabilized by energetic alpha particles on TFTR. With additional instability drive from fast minority ions powered by ICRH, both the global and the core localized TAE modes can be readily destabilized.

52.35.Bj, 52.65.+z, 52.55.Pi
\end{abstract}

DISTRIBUTION OF THIS DOCUMENT IS UNLIMITED

Typeset using REVTEX 
Record fusion powers have recently been achieved in the Tokamak Fusion Test Reactor (TFTR) Deuterium-Tritium (DT) experiments [1]. One novel feature associated with the hot D-T plasmas is the effect of fusion product alpha particles on the stability of reactor grade plasmas. A key question is whether the toroidicity-induced Alfvén eigenmode [2] (TAE) can be destabilized by the energetic alpha particles $[3,4]$ in the TFTR D-T experiments. This could have serious implications for fusion reactors since the TAE instability can induce large fusion alpha particle loss, which could lead to a loss of alpha heating or damage to the first wall. Previous experiments have shown that TAE modes can be strongly destabilized by energetic $D$ ions in neutral beam injection (NBI) heated plasmas $[5,6]$, and by fast hydrogen minority tail ions in Ion Cyctron Radio Frequency (ICRF) Heated plasmas [7].

A search for alpha-driven TAE modes was made during the first phase of TFTR DT operation, when up to $6.3 \mathrm{MW}$ of fusion power was produced in supershot discharges at $B=5 \mathrm{~T}$ and $I=2 \mathrm{MA}$ (e.g., shot\#73268). No significant alpha-driven TAE fluctuations were seen either in the edge magnetic loops or in the reflectometer measurements of internal density fluctuations [1]. Although the magnetic loops did detect a small broad peak in the magnetic fluctuation spectrum in the TAE frequency range [8], the experimental measurements indicate that this fluctuation peak does not correspond to alpha-driven TAE modes. The nature of this peak is still unclear at present.

The stability of TAE modes in the first phase of TFTR D-T experiments is analyzed [9] using the global kinetic/MHD stability code NOVA-K [10,11]. Our numerical results show that the TAE modes are stable in typical TFTR NBI-heated DT plasmas, which is consistent with the experimental observations. Similar results have also been obtained in Ref. 12 using gyrofluid model. However, in a more recent TFTR DT discharge with 7.5MW of fusion power (shot\#76770), our calculations indicate that a new core-localized TAE mode exists, and is nearly unstable due to large alpha particle drive. 
The TAE modes exist with discrete frequencies located inside the shear Alfvén continuum gaps induced by toroidal coupling of different poloidal harmonics. In a cylinder, the shear Alfvén spectrum is given by $\omega^{2}=k_{\|, m}^{2}(r) v_{A}^{2}(r)$, where $v_{A}$ is the Alfvén speed and $k_{\|}=(n-m / q) / R$ is the parallel wave vector with $m / n$ being poloidal/toroidal mode number and q being the safety factor. In a torus, the toroidal mode coupling of $m$ and $m+1$ harmonics results in a gap in the continuum spectrum at the $q=(2 m+1) / 2 n$ surface. An example of toroidal continuum spectrum is shown in Fig. 1(b). In general, the continuum structure depends on the plasma density profile, the q profile, and the pressure profile etc. The existence of the TAE modes depends on the plasma pressure.

There are two types of TAE modes. For the first type, the radial mode structure is global and extended between the half radius and plasma edge, as shown in Fig. 1(a), which plots the radial displacement $\xi_{\psi}$ of a $n=3 \mathrm{TAE}$ as a function of minor radius for several poloidal harmonics. The corresponding $n=3$ shear Alfvén continuum is shown in Fig. 1(b). Most of TAE modes computed for TFTR supershot plasmas are of this type.

Here, we report first results of a second type of modes, called core localized TAE modes, at small magnetic shear and finite plasma beta. Figure 2(a) show such a core localized mode in a TFTR DT plasma (shot \#76770). The corresponding $n=5$ shear Alfvén continuum spectrum is shown in Fig. 2(b). The mode is localized at the first continuum gap near the $r / a=0.2$ surface and has only two appreciable poloidal harmonics with comparable amplitude. The mode frequency is located just above the lower bound of the corresponding continuum gap.

This core localized TAE mode would not exist, according to previous theories [13], where it was shown that the TAE mode exists only when the plasma beta is below a critical value given by $\alpha_{c r i t} \approx s^{2}$, where $s=r d q / q d r$ is the magnetic shear and $\alpha=-2 R q^{2} d p / B^{2} d r$ is proportional to the product of plasma pressure gradient and magnetic curvature. For 
parameters of Fig. 2, we have $s \approx 0.1$ and $\alpha \approx 0.1$ at the $x=\sqrt{\psi}=0.2$ surface. This implies that the critical $\alpha$ value should be much larger than $\alpha_{c r i t} \approx s^{2}$ obtained previously [13]. Indeed, recent analytic work [14] of high-n TAE modes has shown that the critical beta value is enhanced by the finite aspect ratio terms, which were neglected previously. The new critical beta [14] is given by $\alpha_{c r i t}=3 \epsilon+2 s^{2}$, where $\epsilon=r / R$. We note that the finite aspect ratio effect is essential in the limit of small shear (i.e., $s^{2} \ll \epsilon$ ). The analytic scaling of $\alpha_{\text {crit }}=3 \epsilon$ in the small shear limit has been confirmed by our numerical results. Figure 3 shows the eigenfrequency of the $n=5$ core localized mode versus central toroidal beta (dashed line marked with $\omega_{1}$ ) for profiles of Fig. 2. For comparison, the lower bound and the upper bound of the continuum gap at the $r / a=0.2$ surface are also shown (solid lines marked with $\omega_{-}$and $\omega_{+}$respectively). We see that the TAE frequency $\omega_{1}$ approaches the lower bound $\omega_{-}$as the beta increases. The corresponding critical $\alpha$ value is $\alpha=0.14$ which agrees well with the analytic value of $\alpha_{\text {analytic }}=0.15$. Recently, it has been shown that there is another core localized TAE induced by the finite aspect ratio effects [15]. The eigenfrequency of this mode is located near the upper bound of the continuum gap, as shown in Fig. 3 (dashed line marked with $\omega_{2}$ ). The corresponding critical beta value is given by $\alpha_{c}=3 \epsilon-2 s^{2}$ for small shear.

It turns out that in most of high-power TFTR DT discharges, such as the $6.2 \mathrm{MW}$ shot (\#73268), the plasma beta is still too large for the core localized TAE mode to exist, and only the extended TAE can exist. The reasons for the existence of core localized modes in shot \#76770 are that the pressure profile is slightly broader than in typical DT supershot plasmas (see Fig. 4, the central pressures are normalized to the same value.) and that the plasma beta value is lower. This broader profile is due to a slight influx of impurities at the end of the discharge.

Now, we turn to stability calculations of TAE modes for both types using the kinetic MHD stability code NOVA-K. To destabilize TAE, the instability drive associated with the 
alpha particle pressure gradient must overcome damping effects due to all particle species. The NOVA-K code calculates perturbatively the alpha particle drive, the Landau damping of thermal species and beam ions, and the collisional damping of trapped electrons. The non-perturbative radiative damping $[16,17]$ is also included using a boundary layer method [18]. The effects of finite orbit excursion from the flux surface due to magnetic curvature drift are included for both alpha particles and beam ions. All calculations are performed with realistic equilibria (i.e., finite aspect ratio, finite beta and arbitrary flux shape). The continuum damping $[19-21]$ is neglected.

The continuum damping is expected to be small for most cases considered here. For example, there are usually no continuum resonances for global TAE modes, such as shown in Fig. 1. For the core localized TAE modes, the mode frequencies do often intersect with the continua near the plasma edge, such as shown in Fig. 2(b). Nonetheless, the continuum damping is expected to be small due to the localized mode structure.

Our results indicate that the global TAE modes are stable in the TFTR NBI-heated DT plasmas. This is consistent with the experimental observations in the TFTR DT experiments. Figure 5 shows the critical central alpha beta for TAE instability versus toroidal mode number obtained for a DT discharge with 6.2MW of fusion power (shot \#73268). The alpha beta value calculated by TRANSP from experimental profiles [22] is also marked on the figure. We note that the experimental value is about a factor of $1 / 4$ of the calculated $\beta_{\alpha}(0)$ threshold. Analysis of other NBI-heated DT discharges yields similar results. The parameters of shot \#73268 are the major radius $R=252 \mathrm{~cm}$, the minor radius $a=87 \mathrm{~cm}$, the toroidal magnetic field $B=5 T$, the plasma current $I_{p}=2.0 \mathrm{MA}$, the central plasma beta $\beta(0)=4.6 \%$, the volume averaged plasma beta $\langle\beta\rangle=0.89 \%$, the central alpha beta $\beta_{\alpha}(0)=0.18 \%$, the central electron density $n_{e}(0)=7.6 \times 10^{13} \mathrm{~cm}^{-3}$, the ion temperature $T_{i}(0)=28 \mathrm{keV}$, the electron temperature $T_{e}(0)=10.5 \mathrm{keV}$, and the safety factor $q(0)=0.84$ at center and $q(a)=5.1$ at edge. The plasma pressure profile and the $q$ profile are shown 
in Fig. 4 (dashed lines). These profiles are obtained with the TRANSP code [22]. The TRANSP code takes as input the measured temperature profiles, the plasma density profile and total plasma current, etc. It calculates alpha particle pressure profile, safety factor $\mathrm{q}$ profile and all other parameters and profiles. The computed total energy, the Shafranov shifts and total neutron emission agree well with experimental measurements.

We find that the beam ion Landau damping and the radiative damping are the two most important stabilizing mechanisms. For example, the drive and damping increments for the $n=5$ mode considered in Fig. 5 are as follows: the alpha drive $\gamma_{\alpha} / \omega=0.26 \%$, the electron damping rate $\gamma_{e} / \omega=-0.15 \%$, the beam ion Landau damping rate $\gamma_{\text {beam }} / \omega=-0.38 \%$, and the radiative damping $\gamma_{r} / \omega=-0.64 \%$. The thermal ion Landau damping and the electron collisional damping are both negligible. These results are typical for global TAE modes extended between half minor radius and plasma edge where the thermal ion and electron temperatures are relatively low. Physically, the thermal ion Landau damping is small because of low ion temperatures near the edge. Likewise, the electron collisional damping is small due to low electron beta values. On the other hand, the electron Landau damping is appreciable as a result of effective resonance at lower electron temperature. The beam ion Landau damping is large because large beam ion velocity allows sideband resonance at $v_{\|\|} \approx v_{A} / 3$. Furthermore, our numerical results show that the beam ion damping is enhanced greatly by the effects of finite orbit width due to magnetic drift, typically by a factor of 3 to 10. This large enhancement comes from additional sideband resonances induced by drift orbit [23]. Finally, the radiative damping is large due to relatively high mode number. For low- $n$ modes, the radiative damping tends to be smaller than the beam ion damping.

We now turn to the stability of the core localized TAE modes near the lower bound of the continuum gap. For the TFTR discharge (shot \#76770 at 4.3sec) considered above, we find that the $n=5$ core localized mode is weakly unstable due to large alpha particle drive, in the absence of radiative damping. However, the mode becomes marginally stable when 
the radiative damping is included. The ratio of drive and total damping is about 0.7 . The $n=6$ mode has also been calculated and is found to be more stable. The drive and damping increments for the $n=5$ mode are given by $\gamma_{\alpha} / \omega=1.9 \%$, the thermal ion Landau damping $\gamma_{i} / \omega=-0.63 \%$, the beam ion Landau damping $\gamma_{\text {beam }} / \omega=-1.19 \%$, and the radiative damping $\gamma_{r} / \omega=-0.9 \%$. The beam ion Landau damping and the radiative damping are still the two dominant stabilizing mechanisms. These results are obtained with following parameters: the major radius $R=252 \mathrm{~cm}$, the minor radius $a=87 \mathrm{~cm}$, the toroidal magnetic field $B=5 T$, the plasma current $I_{p}=2.5 M A$, the central plasma beta $\beta(0)=3.1 \%$, the volume averaged plasma beta $\langle\beta\rangle=0.82 \%$, the central alpha beta $\beta_{\alpha}(0)=0.24 \%$, the central electron density $n_{e}(0)=7.5 \times 10^{13} \mathrm{~cm}^{-3}$, the ion temperature $T_{i}(0)=22 \mathrm{keV}$, the electron temperature $T_{e}(0)=11 \mathrm{keV}$, and the safety factor $q(0)=0.88$ at center and $q(a)=4.1$ at edge. This central ion temperature (at $4.3 \mathrm{sec}$ ) is considerably lower than the peak value which occurs early in the discharge. The plasma profiles are shown in Fig. 4 (solid lines).

The stability of the core localized TAE mode near the upper bound of the continuum gap has also been calculated. The $n=5$ mode near the upper bound is found to be more stable due to smaller alpha drive as compared to that of the mode near the lower bound.

It is instructive to compare the relative size of drive and dampings of the $\mathbf{n}=5$ core localized mode with that of the $n=5$ extended TAE in Fig. 5. We observe that the alpha particle drive for the core localized mode is much larger. This is because the mode peaks near the center of plasma where the alpha particle pressure gradient is the largest. The beam ion Landau damping is also larger due to higher beam ion beta at the mode peak. The thermal ion Landau damping is now appreciable because higher ion temperature allows more effective wave-particle resonance. Finally, the electron Landau damping and electron collisional damping are small because of higher electron temperature and lower collisional frequency near the plasma center. 
The beam ion Landau Landau damping is sensitive to the beam injection energy. For typical TFTR DT parameters, $v_{D} / v_{A}(0) \approx 0.37$ and $v_{T} / v_{A}(0) \approx 0.30$, where $v_{D}$ and $v_{T}$ is the deuterium beam injection speed and the tritium beam injection speed, respectively. Thus, the deuterium ion damping is usually larger than the tritium ion damping with equal DT concentration. For the $n=5$ core localized TAE considered in this paper, the deuterium damping is much larger than the tritium beam damping. We have numerically studied the effect of injection energy $E_{b}$ on the beam damping. We find that the deuterium beam damping is maximized at $v_{D} / v_{A}(0)=0.33$ (at $E_{b}=80 \mathrm{kev}$ ). The damping falls appreciably when the value of $v_{D} / v_{A}(0)$ decreases below 0.33 . At $v_{D} / v_{A}(0)=0.29$ (at $E_{b}=60 \mathrm{kev}$ ), the damping is reduced by a factor of 22 from the maximum. One the other hand, the damping falls more slowly when $v_{D} / v_{A}(0)$ increases above 0.33 . At $v_{D} / v_{A}(0)=0.47$ (at $E_{b}=160 \mathrm{kev}$ ), the deuterium damping is only reduced by a factor of two. The results for the tritium beam damping are similar. From this analysis, it is clear that the beam damping is only important when $v_{D} / v_{A}(0)>0.3$. This condition can be applied to JET, JT-60U or ITER, where neutral beam heating could be used to stabilize TAE modes.

Up until now, we have only considered instability drive from alpha particles in TFTR DT experiments without ICRH. However, with ICRH, additional drive could come from fast minority tail ions with their energy on the order of $M e v$. This additional drive can potentially be very important since ICRH power $(\sim 5 M W)$ is typically much larger than the alpha particle power $(<2 M W)$. Thus, it is instructive to compare the minority ion drive with alpha drive. For typical parameters, we find that the ICRH drive is much larger than the alpha drive for global TAE modes, but for core localized TAE modes, the ICRH drive is comparable to the alpha drive. For example, the calculated ICRH drive for the $n=5$ global TAE mode in the discharge (\#73268) would be seven times larger than the alpha drive if $5 M W$ of ICRH were present. On the other hand, for the $n=5$ core localized TAE in the discharge (\#76770), the ICRH drive would be $25 \%$ smaller than the alpha drive. These results are obtained by assuming following parameters for hydrogen minority ICRF heating: 
the central minority ion beta $\beta_{h}(0)=0.7 \%$, the central tail temperature $T_{h}(0)=0.5 \mathrm{Mev}$, and the minoritiy ion pressure profile $P_{h} \propto(1-\sqrt{\Psi} / 0.5)^{2}$ for $\sqrt{\Psi}<0.5$ and $P_{h}=0$ for $\sqrt{\Psi}>0.5$. These results show that the alpha particles with a smaller power $(\sim 1.5 \mathrm{MW})$ can actually provide a similar drive for core localized TAE mode as compared with minority ions powered by ICRH $(\sim 5 M W)$. This is because the particle distribution of minority ions is quite different from that of isotropic alpha population. It is know that the finite drift orbit width effects can reduce the fast particle drive. Since minority ions are mostly trapped particles, this stabilizing orbit effect is much stronger, as shown by our NOVA-K results. From this analysis, we conclude that TAE modes can be readily destabilized in TFTR DT eperiments with ICRH.

So far, there is no direct experimental evidence that the core localized TAE mode exists in the TFTR DT plasmas. In the particular DT discharge (shot \#76770) where a $n=5$ core localized TAE mode is calculated to be nearly unstable, there is no reflectometer data in the core. It should also be pointed out that these core localized TAE modes would not be detected by the edge magnetic coils since they are so localized near the center of the plasma. However, in the TFTR ICRF heated deuterium plasmas, there are indications from the reflectometer data that the core localized TAE modes do exist in these plasmas. Figure 6 shows the fluctuation spectrum in the range of frequencies of TAE modes in an ICRF heated TFTR deuterium plasma with both microwave reflectometery and mirnov measurements [24]. At $r / a \sim 0.4$, the reflectometer observes the same spectrum of fluctuations as measured by Mirnov coils. On the contrary, near the center of the plasma where $q<1$, the reflectometer measures fluctuations in the TAE range of frequencies which are not observed on the Mirnov signals. This suggests the existence of core localized TAE modes. The results of NOVA-K code have indeed confirmed the existence of several core localized modes in this particular discharge. The calculated mode frequencies and stability threshold agree with the experimental observations.

In future TFTR DT experiments, it might be useful to actively destabilize TAE modes in order to study their instability property and associated transport. One way to do it is 
reducing the beam ion Landau damping. Our results show that the beam damping can be reduced significantly with a lower beam injection energy due to resonance detuning. Another way to excite TAE is increasing the alpha particle drive. This can be done by modifying the pressure profile such that the core localized TAE mode can exist. Additional TAE instability driven such as ICRH fast tail ion drive can greatly enhance the possibility of TAE instability . In the International Thermonuclear Engineering Reactor (ITER), our initial calculations indicate that high- $n$ TAE modes are unstable.

In conclusion, global TAE modes are found to be stable in the TFTR NBI-heated DT plasmas without ICRH. However, a new core localized TAE mode is shown to exist at small magnetic shear and finite plasma beta, and can be unstable due to large alpha particle drive. Additional instability drive from fast minority ions powered by ICRH can destabilize both global TAE modes and core localized TAE modes.

The authors gratefully acknowledge the support of the TFTR group. This work is supported by the U.S. Department of Energy under Contract No. DE-AC02-76-CHO-3073. 


\section{REFERENCES}

[1] J. D. Strachan et al., Phys. Rev. Lett., 72, 3526 (1994).

[2] C. Z. Cheng, L. Chen, and M. S. Chance, Ann. Phys. (N. Y.) 161, 21 (1985); C. Z. Cheng and M. S. Chance, Phys. Fluids 29,3695 (1986).

[3] G. Y. Fu and J. W. Van Dam, Phys. Fluids B1, 1949 (1989).

[4] C. Z. Cheng, G. Y. Fu, and J. W. Van Dam, in Proceedings of Workshop on Theory of Fusion Plasmas, Chexbres, Switzerland, 1988(ed, J. Vaclavik, F. Troyon, and E. Sindoni, Societa Italiana di Fisica, Bologna, 1989), p. 259

[5] K. L. Wong et al., Phys. Fluids B4, 2122 (1992).

[6] W. W. Heidbrink et al., Nucl. Fusion 31, 1635 (1991).

[7] J. R. Wilson et al., in Proceedings of the Fourteen International Conference on Plasma Physics and Controlled Nuclear Fusion Research, Wurzburg, Germany, September, 1992 (International Atomic Energy Agency), IAEA-CN-56/E-2-2.

[8] E. Fredrickson et al., in Proceedings of the Fifteen International Conference on Plasma Physics and Controlled Nuclear Fusion Research, Seville, Spain, October, 1994 (International Atomic Energy Agency), paper IAEA-CN/60/A-2-II-5.

[9] C. Z. Cheng et al., in Ref. 8, paper IAEA-CN-60/D3-III-2.

[10] C. Z. Cheng, Phys. Reports 211, 1 (1992).

[11] G. Y. Fu, C. Z. Cheng and K. L. Wong, Phys. Fluids B5, 4040 (1993).

[12] D. A. Spong et al., in Ref. 8, paper IAEA-CN-60/D-P-II-3.

[13] G. Y. Fu and C. Z. Cheng, Phys. Fluids B2, 985 (1990).

[14] G. Y. Fu, Phys. Plasmas 2, 1029 (1995).

[15] H. L. Berk et al., accepted by Phys. Plasmas. 
[16] R. Mett and S. Mahajan, Phys. Fluids B 4, 2885 (1992).

[17] J. Candy and M. N. Rosenbluth, Phys. Plasmas 1, 356 (1994).

[18] H. L. Berk, R. R. Mett, and D. M. Lindberg, Phys. Fluids B 5, 3969 (1993).

[19] H. L. Berk, J. W. Van Dam, Z. Guo, and D. M. Lindberg, Phys. Fluids B4, 1806 (1992).

[20] F. Zonca and L. Chen, Phys. Rev. Lett., 68, 592(1992)

[21] M. N. Rosenbluth, H. L. Berk, D. M. Lindberg, and J. W. Van Dam, Phys. Rev. Lett., 68, $596(1992)$.

[22] R. Budny et al., Nucl. Fusion 34, 1247 (1994).

[23] G. Y. Fu and C. Z. Cheng, Phys. Fluids B4, 3722 (1992).

[24] R. Nazikian and E. Mazzucato, Bull. Am. Phys. Soc. 38, 1906 (1993). 


\section{FIGURES}

FIG. 1. (a)The radial displacement $\xi_{\psi}$ of a $n=3 \mathrm{TAE}$ mode as a function of plasma minor radius; (b)The $n=5$ shear Alfvén continuum spectrum $\left(\omega / \omega_{A}\right)^{2}$, where $\omega_{A}=v_{A}(0) / q_{a} R$.

FIG. 2. (a)The radial displacement $\xi_{\psi}$ of a $n=5 \mathrm{TAE}$ mode as a function of plasma minor radius; (b)The $n=5$ shear Alfvén continuum spectrum $\left(\omega / \omega_{A}\right)^{2}$.

FIG. 3. The eigen frequencies of the $n=5$ core localized TAE modes (dashed lines) as a function of central toroidal beta. The lower and upper bound of the corresponding continuum gap are shown in solid lines.

FIG. 4. The plasma pressure profiles and q profiles as a function of plasma minor radius for the TFTR DT discharge \#73268 (dashed lines) and the discharge \#76770 (solid lines).

FIG. 5. The critical central alpha beta value as a function of toroidal mode number for the TFTR DT discharge \#73268.

FIG. 6. Spectrum of observed fluctuations in the TAE range of frequencies during ICRF heating in TFTR plasmas. (a) edge magnetic fluctuations, (b) reflectometer measurements of density fluctuations at $r / a \sim 0.4$, and (c) reflectometer measurements of density fluctuations at $r / a \sim 0.1$. 


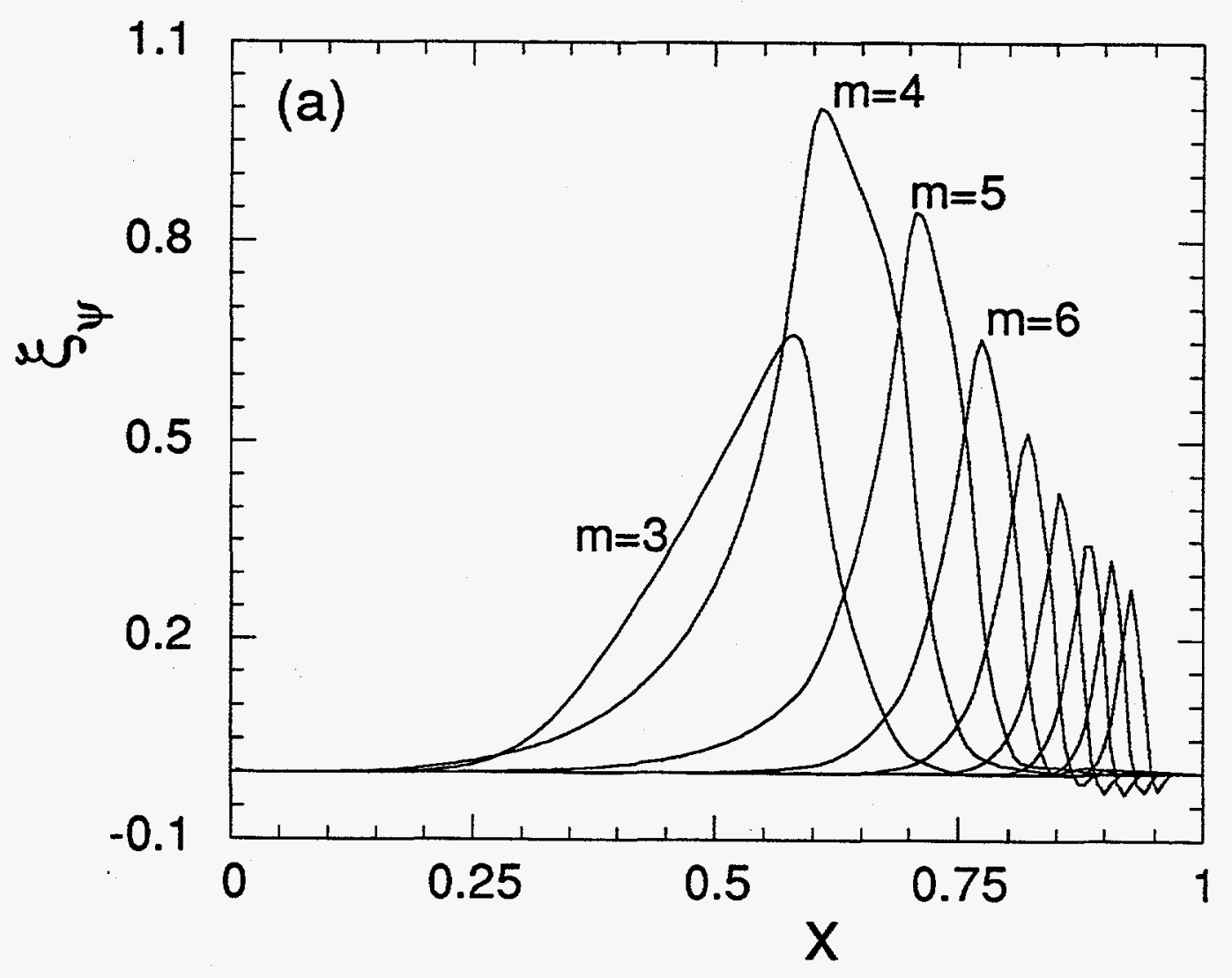

Fig. 1(a) 


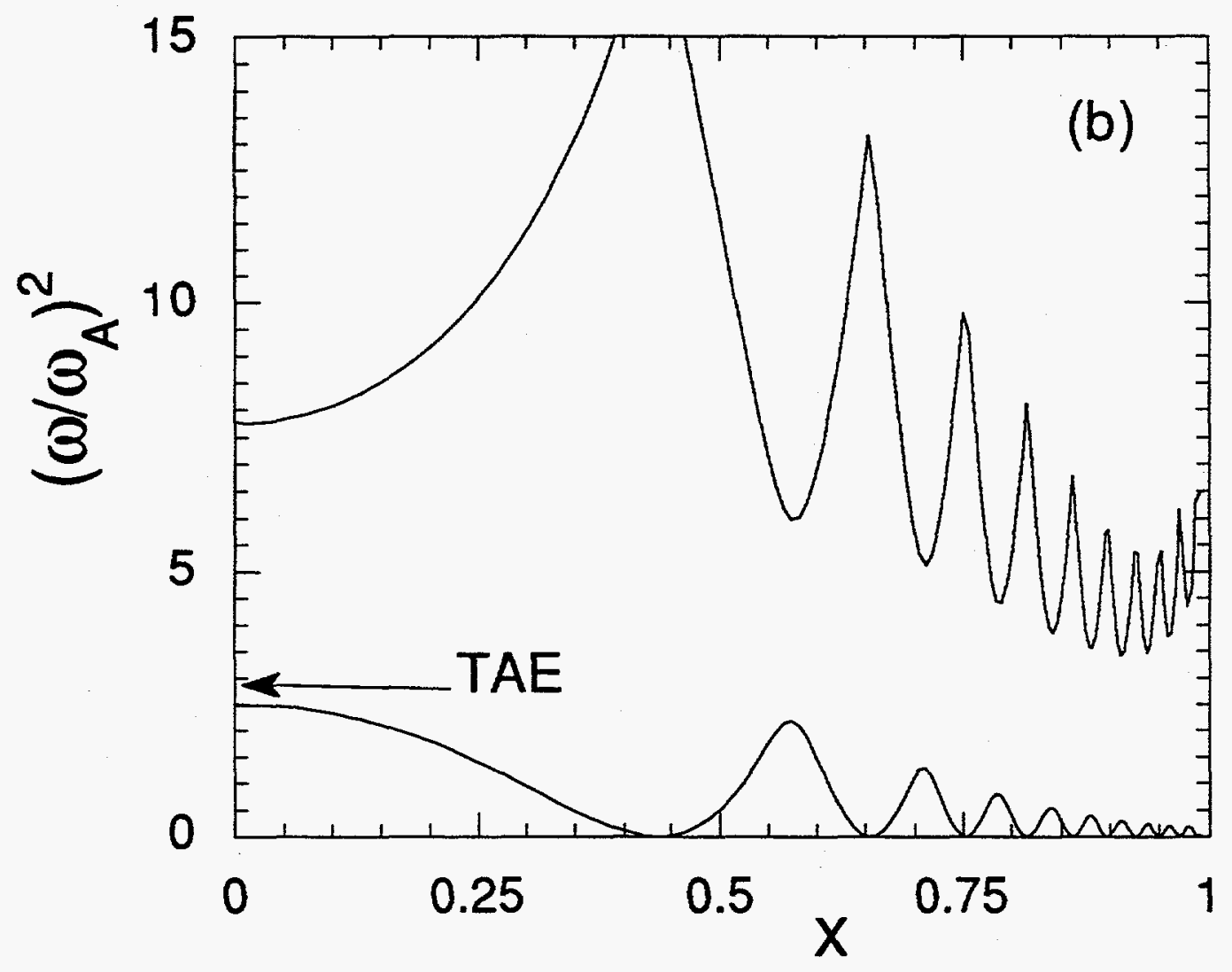

Fig. 1(b) 


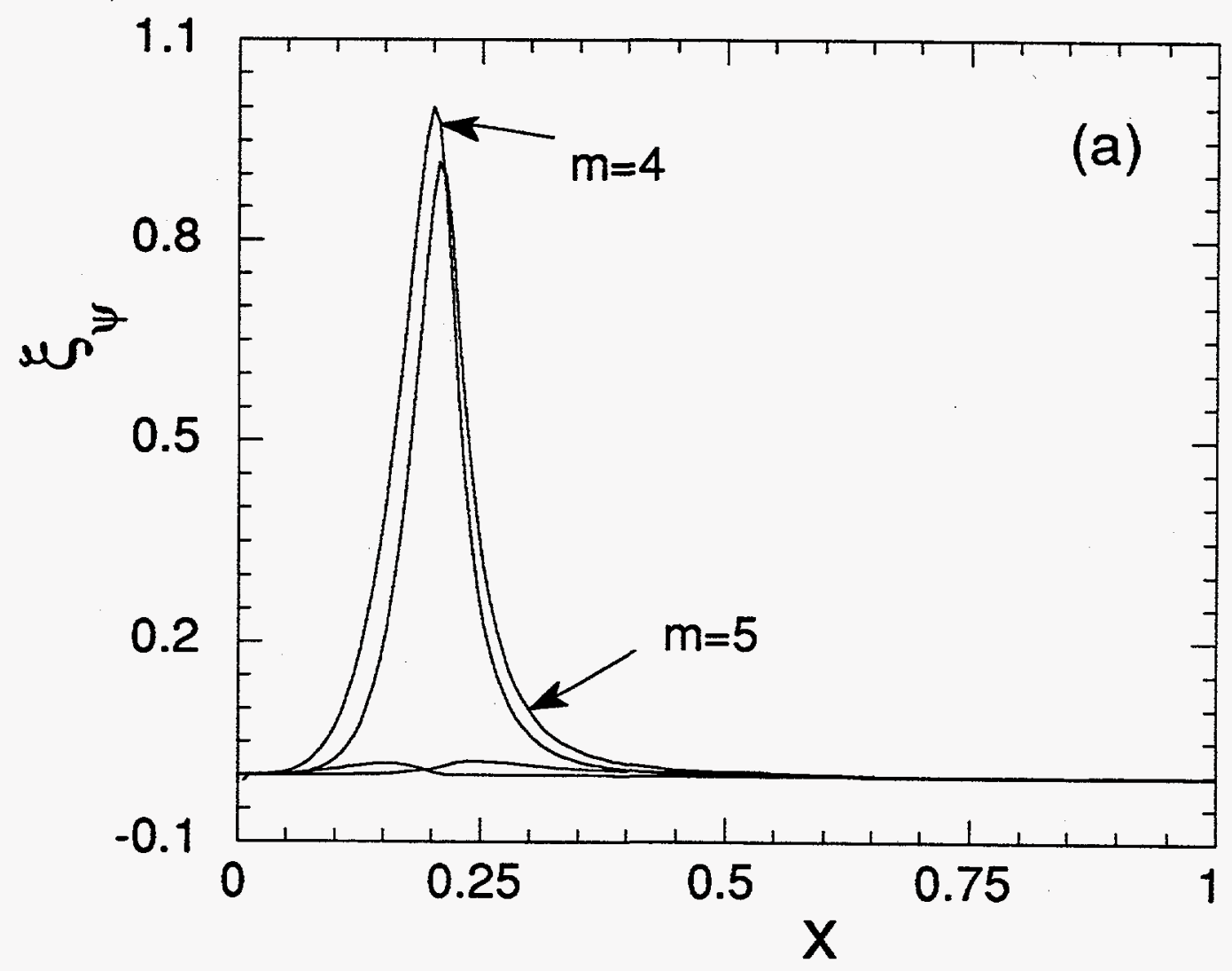

Fig. 2(a) 


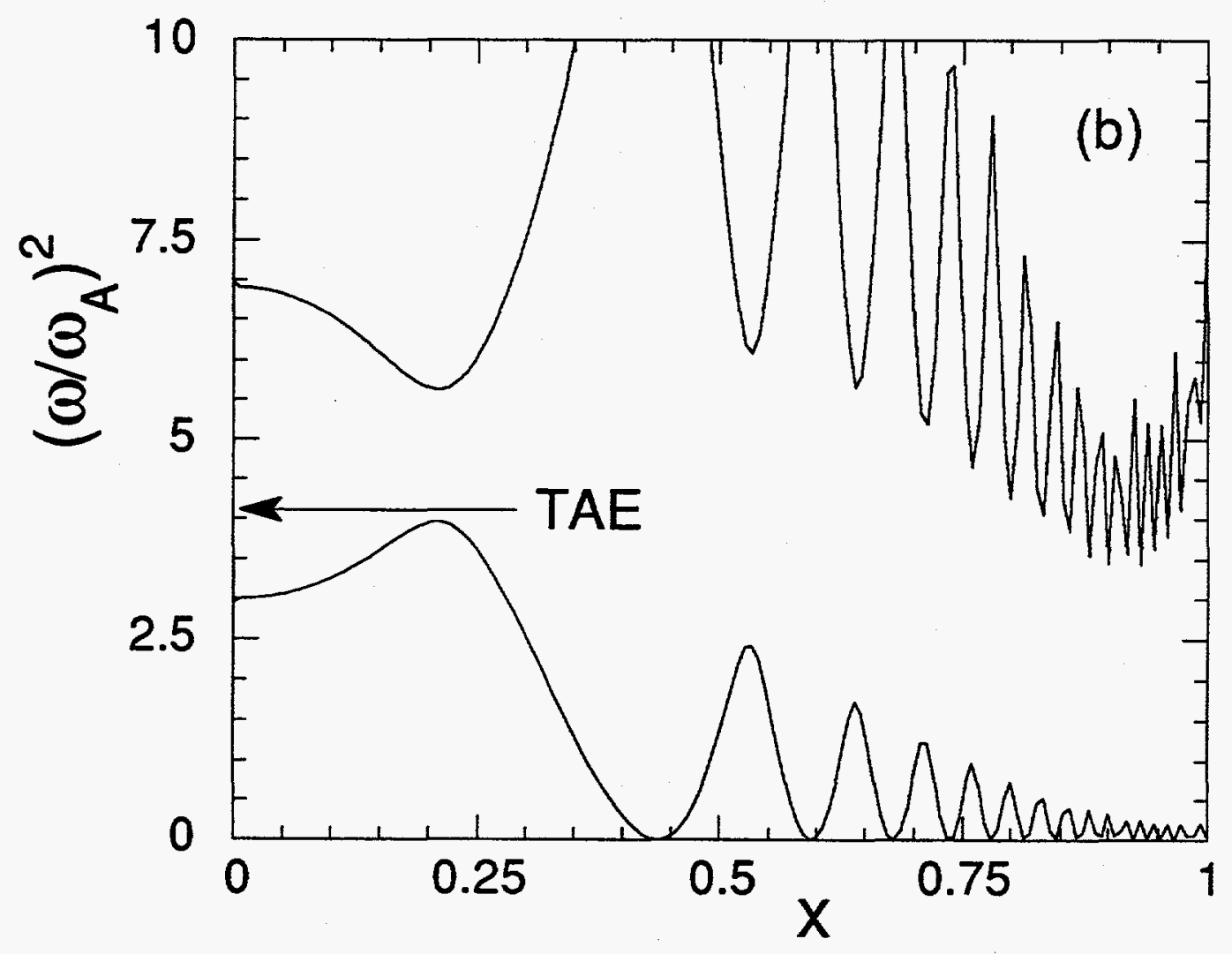

Fig. 2(b) 


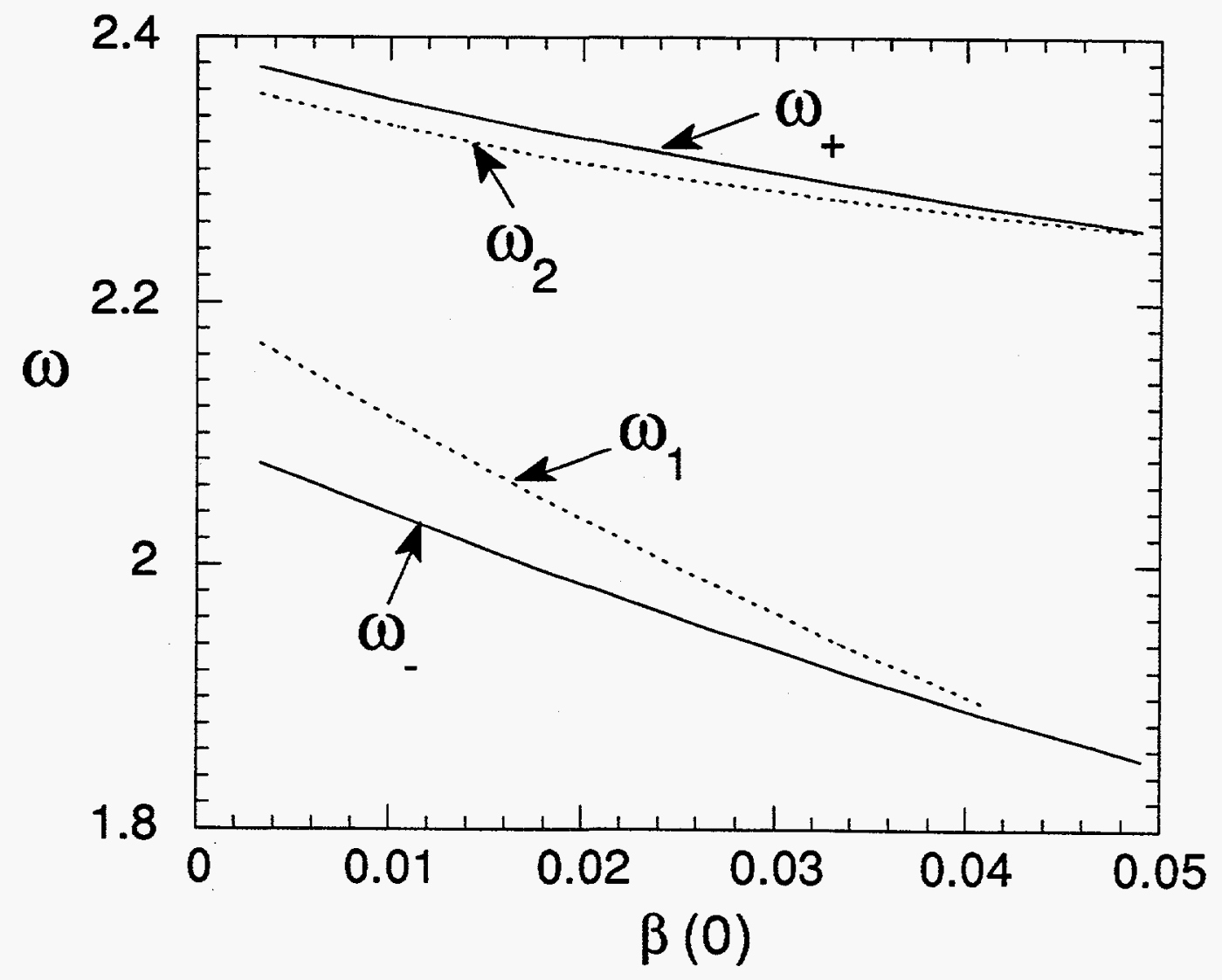

Fig. 3 


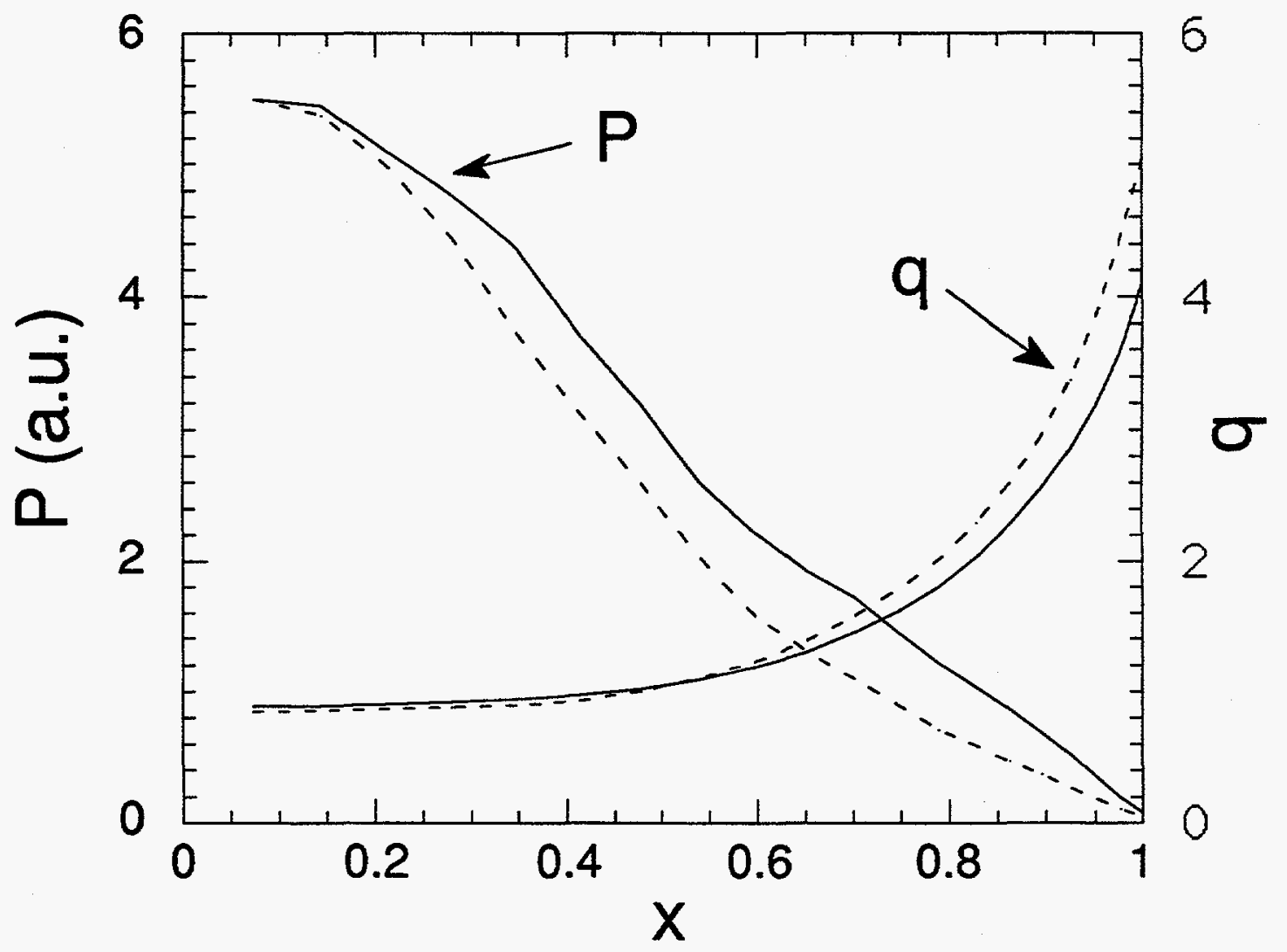

Fig. 4 


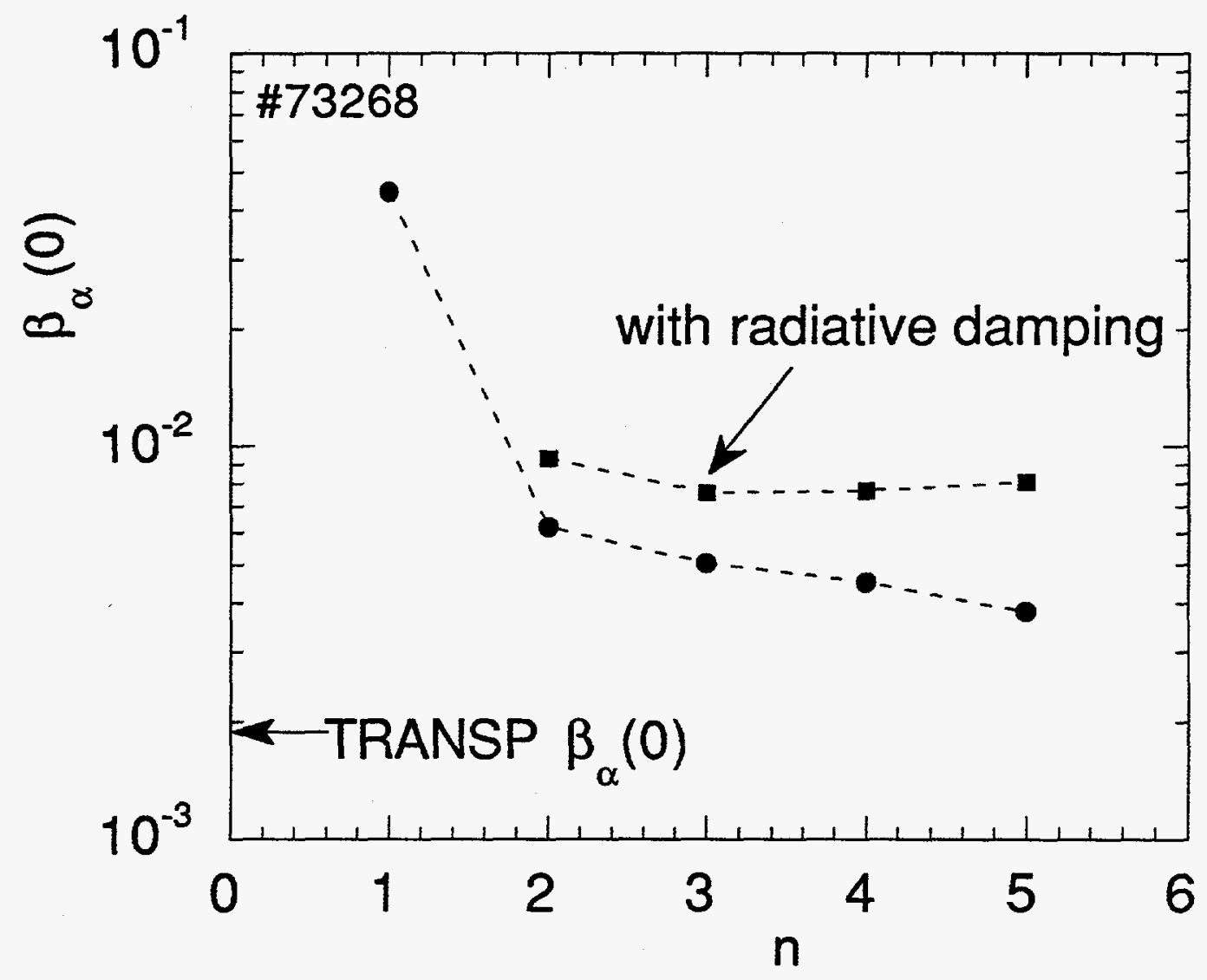

Fig. 5 

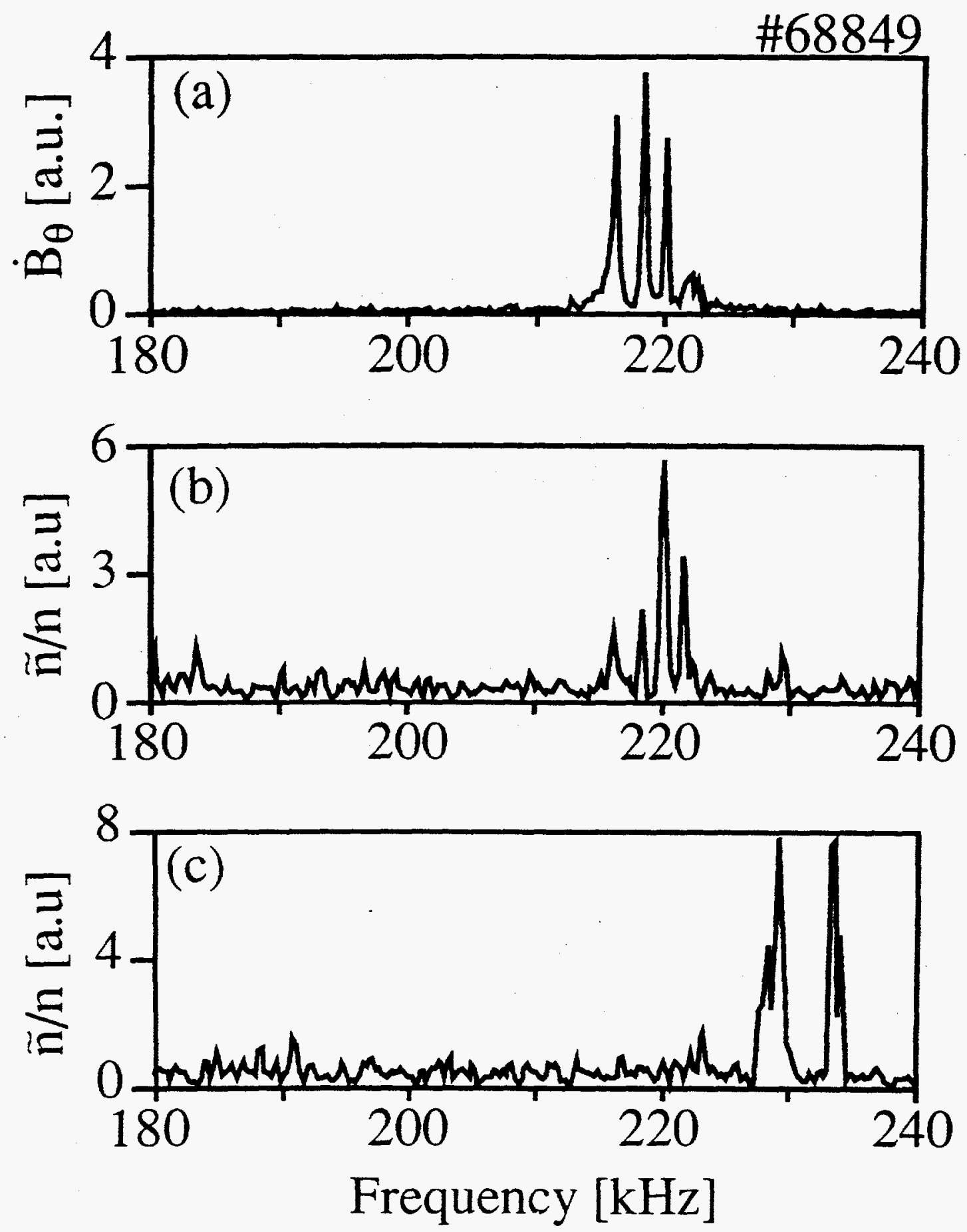

Fig. 6 
Dr. F. Paoloni, Univ. of Wollongong, AUSTRALIA

Prof. R.C. Cross, Univ. of Sydney, AUSTRALIA

Plasma Research Lab., Australian Nat. Univ., AUSTRALIA

Prof. I.R. Jones, Flinders Univ, AUSTRALIA

Prof. F. Cap, Inst. for Theoretical Physics, AUSTRIA

Prof. M. Heindler, Institut für Theoretische Physik, AUSTRIA

Prof. M. Goossens, Astronomisch Instituut, BELGIUM

Ecole Royale Militaire, Lab. de Phy. Plasmas, BELGIUM

Commission-European, DG. XII-Fusion Prog., BELGIUM

Prof. R. Bouciqué, Rijksuniversiteit Gent, BELGIUM

Dr. P.H. Sakanaka, Instituto Fisica, BRAZIL

Prof. Dr. I.C. Nascimento, Instituto Fisica, Sao Paulo, BRAZIL Instituto Nacional De Pesquisas Espaciais-INPE, BRAZIL

Documents Office, Atomic Energy of Canada Ltd., CANADA

Ms. M. Morin, CCFWTokamak de Varennes, CANADA

Dr. M.P. Bachynski, MPB Technologies, Inc., CANADA

Dr. H.M. Skarsgard, Univ. of Saskatchewan, CANADA

Prof. J. Teichmann, Univ. of Montreal, CANADA

Prof. S.R. Sreenivasan, Univ. of Calgary, CANADA

Prof. R. Marchand, INRS-Energie et Materiaux, CANADA

Dr. R. Bolton, Centre canadien de fusion magnétique, CANADA

Dr. C.R. James, Univ. of Alberta, CANADA

Dr. P. Lukác, Komenského Universzita, CZECHO-SLOVAKIA

The Librarian, Culham Laboratory, ENGLAND

Library, R61, Rutherford Appleton Laboratory, ENGLAND

Mrs. S.A. Hutchinson, JET Library, ENGLAND

Dr. S.C. Sharma, Univ. of South Pacific, FIJI ISLANDS

P. Mähönen, Univ. of Helsinki, FINLAND

Prof. M.N. Bussac, Ecole Polytechnique, FRANCE

C. Mouttet, Lab. de Physique des Milieux lonisés, FRANCE

J. Radet, CEN/CADARACHE - Bat 506, FRANCE

Prof. E. Economou, Univ. of Crete, GREECE

Ms. C. Rinni, Univ. of loannina, GREECE

Preprint Library, Hungarian Academy of Sci., HUNGARY

Dr. B. DasGupta, Saha Inst. of Nuclear Physics, INDIA

Dr. P. Kaw, Inst. for Plasma Research, INDIA

Dr. P. Rosenau, Israel Inst. of Technology, ISRAEL

Librarian, International Center for Theo Physics, ITALY

Miss C. De Palo, Associazione EURATOM-ENEA, ITALY

Dr. G. Grosso, Istituto di Fisica del Plasma, ITALY

Prof. G. Rostangni, Istituto Gas Ionizzati Del Cnr, ITALY
Dr. H. Yamato, Toshiba Res \& Devel Center, JAPAN

Prof. I. Kawakami, Hiroshima Univ., JAPAN

Prof. K. Nishikawa, Hiroshima Univ., JAPAN

Librarian, Naka Fusion Research Establishment, JAERI, JAPAN

Director, Japan Atomic Energy Research Inst., JAPAN

Prof. S. Itoh, Kyushu Univ., JAPAN

Research Info. Ctr., National Instit. for Fusion Science, JAPAN

Prof. S. Tanaka, Kyoto Univ., JAPAN

Library, Kyoto Univ., JAPAN

Prof. N. Inove, Univ. of Tokyo, JAPAN

Secretary, Plasma Section, Electrotechnical Lab., JAPAN

Dr. O. Mitarai, Kumamoto Inst. of Technology, JAPAN

Dr. G.S. Lee, Korea Basic Sci. Ctr., KOREA

J. Hyeon-Sook, Korea Atomic Energy Research Inst., KOREA

D.I. Choi, The Korea Adv. Inst. of Sci. \& Tech., KOREA

Leandro Melendez Lugo, Inst. Nac'l. de Inves. Nucl, MEXICO

Prof. B.S. Liley, Univ. of Waikato, NEW ZEALAND

Inst of Physics, Chinese Acad Sci PEOPLE'S REP. OF CHINA Library, Inst. of Plasma Physics, PEOPLE'S REP. OF CHINA

Tsinghua Univ. Library, PEOPLE'S REPUBLIC OF CHINA

Z. Li, S.W. Inst Physics, PEOPLE'S REPUBLIC OF CHINA

Prot. J.A.C. Cabral, Instituto Superior Tecnico, PORTUGAL

Prof. M.A. Hellberg, Univ. of Natal, S. AFRICA

Prof. D.E. Kim, Pohang inst. of Sci. \& Tech., SO. KOREA

Prof. C.I.E.M.A.T, Fusion Division Library, SPAIN

Dr. L. Stenflo, Univ. of UMEA, SWEDEN

Library, Royal Inst. of Technology, SWEDEN

Prof. H. Wilhelmson, Chalmers Univ. of Tech., SWEDEN

Centre Phys. Des Plasmas, Ecole Polytech, SWITZERLAND

Bibliotheek, Inst. Voor Plasma-Fysica, THE NETHERLANDS

Asst. Prof. Dr. S. Cakir, Middle East Tech. Univ., TURKEY

Dr. V.A. Glukhikh,Sci. Res. Inst. Electrophys.l Apparatus, USSR

Dr. D.D. Ryutov, Siberian Branch of Academy of Sci., USSR

Dr. G.A. Eliseev, I.V. Kurchatov Inst., USSR

Librarian, The Ukr.SSR Academy of Sciences, USSR

Dr. L.M. Kovrizhnykh, Inst. of General Physics, USSR

Kemforschungsanlage GmbH, Zentralbibliothek, W. GERMANY

Bibliothek, inst. Für Plasmaforschung, W. GERMANY

Prof. K. Schindier, Ruhr-Universitát Bochum, W. GERMANY

Dr. F. Wagner, (ASDEX), Max-Planck-Institut, W. GERMANY

Librarian, Max-Planck-Institut, W. GERMANY 